\title{
Efficient Derivation and Inducible Differentiation of Expandable Skeletal Myogenic Cells from Human ES and Patient-Specific iPS Cells
}

\author{
Sara M. Maffioletti ${ }^{1^{*}}$, Mattia F.M. Gerli ${ }^{1^{*}}$, Martina Ragazzi ${ }^{1}$, Sumitava Dastidar $^{2}$, \\ Sara Benedetti ${ }^{1,3}$, Mariana Loperfido ${ }^{2,4}$, Thierry VandenDriessche ${ }^{2,4}$, Marinee \\ K. Chuah ${ }^{2,4}$ and Francesco Saverio Tedesco ${ }^{1, \#}$ \\ ${ }^{1}$ Department of Cell and Developmental Biology, University College London, WC1E 6DE London, UK. \\ ${ }^{2}$ Department of Gene Therapy \& Regenerative Medicine, Free University of Brussels (VUB), Brussels, \\ Belgium. \\ ${ }^{3}$ Institute of Child Health, University College London, WC1N 1EH, London, UK. \\ ${ }^{4}$ Department of Cardiovascular Sciences, Center for Molecular and Vascular Biology, University of Leuven \\ (KU Leuven), Leuven, Belgium. \\ *These authors contributed equally to this work. \\ \#Corresponding author (FST): Department of Cell and Developmental Biology, University College London, \\ Rockefeller Building, WC1E 6DE London, UK; Tel +44 2031082383; Fax +44 20767 97349; \\ f.s.tedesco@ucl.ac.uk \\ E-mail addresses: s.maffioletti@ucl.ac.uk, m.gerli@ucl.ac.uk, m.ragazzi@ucl.ac.uk, \\ dastidar.sumit@gmail.com, s.benedetti@ucl.ac.uk, mariana.loperfido@med.kuleuven.be, \\ thierry.vandendriessche@vub.ac.be, marinee.chuah@vub.ac.be and f.s.tedesco@ucl.ac.uk
}

\begin{abstract}
Skeletal muscle is the most abundant human tissue; therefore, an unlimited availability of myogenic cells is relevant for regenerative medicine and drug development. Here we detail a protocol to derive myogenic cells from human embryonic stem (ES) and induced pluripotent stem (iPS) cells in three weeks. We also provide evidence for its extension to human iPS cells cultured without feeder cells. The procedure, which does not require embryoid bodies or prospective isolation, entails four steps with different culture densities, media and surface coating. Pluripotent stem cells are first differentiated into expandable cells resembling human mesoangioblasts. Subsequently, transient MyoD induction efficiently drives myogenic differentiation into multinucleated myotubes. Patient-specific cells obtained with this protocol have been genetically corrected and were proven to have therapeutic potential in dystrophic mice. This platform is amenable for gene and cell therapy, tissue engineering and disease modelling.
\end{abstract}




\section{INTRODUCTION}

Skeletal muscle regenerates after injuries or during chronic diseases such as muscular dystrophies. Muscular dystrophies are a heterogeneous group of disorders characterised by progressive muscle wasting that causes serious mobility and breathing impairment, leading to death in the most severe forms ${ }^{1}$. Regeneration relies mainly on adult stem cells called satellite cells ${ }^{2}$, which reside underneath the myofibres' basal lamina and generate committed progenitors called myoblasts. At present, there is no definitive cure available for such diseases, although a number of experimental treatments are undergoing preclinical and clinical experimentation ${ }^{2,3}$. Among these, cell therapy aims at providing a non-mutated copy of the gene of interest while restoring the lost tissue and (ideally) its stem/progenitor cell compartment. However, despite the promising results obtained in murine models, clinical trials with myoblast transplantation in patients with muscular dystrophy indicate that their use might be restricted to local delivery ${ }^{4}$. Other myogenic cells can also be isolated from skeletal muscle ${ }^{2}$. Among them, pericyte-derived mesoangioblasts ${ }^{5}$ are a promising population that can be delivered systemically; they are currently undergoing clinical experimentation for Duchenne Muscular Dystrophy (DMD, OMIM \#310200; EudraCT no. 2011-000176-33). Although allogeneic cell therapy could be a feasible option, autologous transplantation would be desirable, as it would avoid or reduce immune-suppressive therapy for patients. However, the cycles of degeneration-regeneration of dystrophic muscle challenges the availability and proliferation potential of tissue-derived progenitors for autologous therapies $^{6-11}$ Additionally, the large-scale expansion required to generate adequate cell numbers for drug screening platforms and tissue engineering also challenges the proliferative potential of myogenic cells derived from adult muscle, posing a major hurdle for the development of successful therapeutic interventions. Induced pluripotent stem (iPS) cells could provide a solution to this limitation $^{12}$. Nonetheless, safe and efficient methods to differentiate iPS cells towards specific cell lineages need to be developed and validated. 
In order to overcome the above-mentioned limitations, we have developed a protocol to differentiate human pluripotent stem cells into an expandable cell type similar to mesoangioblasts that efficiently generates skeletal muscle upon induction of the myogenesis regulator $\mathrm{MyoD}^{11}$. Pre-existing methods to generate vascular cells from human embryonic stem (ES) cells facilitated the initial setup of the protocol ${ }^{13}$. We have demonstrated that these iPS cell-derived, patientspecific, myogenic cells can be genetically corrected, expanded in culture and differentiated into multinucleated myotubes in vitro, contributing to skeletal muscle regeneration by restoring the missing gene and protein upon transplantation in dystrophic animals ${ }^{11,14}$. Additionally, similarly to their tissuederived counterpart, also human iPS cell-derived mesoangioblast-like cells exert immunosuppressive effects on $\mathrm{T}$ cell proliferation ${ }^{15}$, a relevant finding for their possible use in cell therapies. Notably, when this protocol was utilised to differentiate mouse iPS cells, transplantation of the derived progeny resulted in amelioration of muscle function of the treated dystrophic mice ${ }^{11}$.

In this paper we detail the experimental procedure that allows the derivation of mesoangioblast-like myogenic cells defined as HIDEMs (human iPS cell-derived mesoangioblast-like cells) from healthy and disease-specific human iPS cells. This is achieved via a stepwise differentiation process consisting of sequential monolayer cultures over 3 weeks. New evidence of extension of this procedure to human iPS cells cultured without feeder cells (feeder-free/FF HIDEMs) and to human ES cells (HEDEMs; human ES cells derived mesoangioblast-like cells) is also provided. These cells are expandable in culture and non-tumorigenic in vivo. Efficient myogenic differentiation is induced synchronously in the culture via Tamoxifen-driven activation of the myogenesis regulator MyoD, which is also a tumour suppressor gene ${ }^{16,17}$. Please refer to Figure 1 for a schematic view of the entire protocol.

Although this method was originally established for gene and cell therapy of muscular dystrophies ${ }^{11}$, it is applicable to any other platform requiring largescale production of myogenic cells, such as high-throughput drug screening, 
tissue engineering and regenerative medicine. Overall, its adaptability to patientspecific iPS cells makes it relevant also for the promising area of personalised medicine $^{18}$.

\section{Comparison with alternative protocols for derivation of myogenic cells from human pluripotent stem cells}

Different protocols have been developed over the past years to obtain myogenic cells from pluripotent stem cells. Most of them require embryoid body formation, transgene overexpression and/or prospective isolation. Barberi and colleagues derived CD73-positive mesenchymal precursors from human ES cells and then purified the NCAM-positive (also known as CD56) myogenic fraction ${ }^{19}$. Later, different groups derived myogenic cells from human pluripotent stem cells by means of embryoid body formation ${ }^{20,21}$, transgene overexpression $\left(\operatorname{Pax} 7^{20}\right.$ and $M_{y o D}{ }^{21-23}$ ) and enrichment by fluorescence activated cell sorting $(F A C S)^{20}$. Interesting results were produced by treatments with growth factors and small molecules ${ }^{24,25}$ but they still need to be validated with muscle function tests in vivo. As a general consideration, all the published protocols generate a myogenic cell population with variable efficiency and after a prolonged time in culture.

Some of these alternative protocols showed convincing engraftment of human pluripotent stem cell-derived myogenic cells in murine skeletal muscle (e.g. Goudenege et al. ${ }^{22}$ ); however, only Darabi and colleagues provided functional evidence of the therapeutic potential of human pluripotent stem cell-derived myogenic cells intramuscularly transplanted in dystrophic mice ${ }^{20}$ (although without genetic correction).

Therefore, even if other methods are already available to generate myogenic cells from pluripotent stem cells, to our knowledge our protocol is at present the only published evidence of generation of genetically corrected patient-specific iPS cell-derived myogenic cells that engraft dystrophic muscle and differentiate into myofibres in vivo ${ }^{11}$. This feature, together with the possibility of locoregional intra-arterial delivery, makes these cells a possible future candidate for the treatment of muscle disorders such as $\mathrm{DMD}^{11,14}$. 


\section{From pluripotency to mesoangioblast-like cells}

Undifferentiated cultures of human ES and iPS cells represent the starting population of the protocol. Pluripotent cells need to be cultured under appropriate conditions and must not contain a significant population of differentiated cells, which might compromise the success of the procedure. Adequate cell pluripotency needs to be assessed prior to the start of the procedure as a prerequisite for an effective outcome. This includes expression analysis of pluripotency genes (e.g. Nanog, Oct3/4, KIf4) and in vitro and in vivo analysis of differentiation potential ${ }^{26}$ (e.g. teratoma-formation assay).

Both feeder-dependent and feeder-free iPS cultures have been used with comparable results in terms of efficiency of differentiation; a few steps have been refined specifically for feeder-free cultures. Although some feeder cells can contaminate the feeder-dependent cultures in the first steps of the derivation protocol, they are then rapidly lost due to their mitotic inactivation and were never found in the final product. An overview of representative cell morphology at different steps is shown in Figure 2.

In detail, feeder-dependent human $\mathrm{iPS}^{11}$ and ES cells (Shef $6{ }^{27}$ ) were cultured on a layer of mitomycin-treated mouse embryonic fibroblasts plated on Matrigel (iPS cells) or gelatin (ES cells) in KO DMEM-based medium. For passaging, feeder-dependent pluripotent clones were detached with a solution of $1 \mathrm{mg} / \mathrm{ml}$ collagenase IV in KO DMEM and then split 1:3 - 1:5. Feeder-free human iPS cells (System Biosciences, USA \#SC102A-1N; similar results have been obtained also with an additional line) were cultured in Essential 8 medium on a Geltrex matrix. For passaging, feeder-free cells were detached with $50 \mathrm{mM}$ EDTA in PBS and subsequently passaged at a split ratio of 1:4-1:6. We do not have any reason to believe that presence or absence of a feeder layer would affect the derivation efficiency of mesoangioblast-like cells and the quality of the results, provided that the iPS cell cultures are kept under appropriate undifferentiated conditions. 
The first step of the protocol entails the disaggregation of pluripotent colonies to single cells. According to the results obtained across more than 20 different lines, this is the most critical step of the protocol in terms of cell survival. Pre-treatment of the cells with ROCK inhibitor $^{28}$ significantly decreases cell mortality in this step of the protocol. Cell populations that are particularly sensitive to single-cell disaggregation might yield suboptimal results at this step and you might need to repeat it a few times before obtaining a satisfactory outcome. As a general rule, even if some cell death is present in the culture one day after single cell passaging, as long as the cell-plating density is appropriate, the results of the protocol will not be negatively affected.

Culturing dissociated pluripotent cells on a Matrigel-coated surface exposes them to laminin, collagen IV, heparan sulfate proteoglycans and entactin/nidogen, all components of the vascular and muscle basement membranes ${ }^{29}$. Notably, Matrigel itself is known to promote vascular cell differentiation in vitro and in vivo in angiogenesis assays ${ }^{30,31}$ as well as differentiation of myogenic cells ${ }^{32}$. Importantly laminin and collagen IV, besides being the two main components of Matrigel, are produced by myoblasts and muscle fibroblasts and assembled on the surface of myotubes during differentiation ${ }^{33}$. They represent also the two main components of the extracellular matrix (ECM) of the muscle satellite stem cell niche ${ }^{34}$. Therefore we hypothesised that the exposure to the above ECM molecules at both cell densities and in media similar to those established for human ES differentiation into vascular smooth muscle cells ${ }^{13}$, could prime pluripotent cells toward the mesodermal, vascular and myogenic lineages. Upon transferring of the cultures into a medium optimised to culture human mesoangioblasts ${ }^{35}$, the above cells are then maintained in a status that allows their in vitro expansion. Human ES/iPS cells derived mesoangioblast-like cells will be referred from now on as HEDEMs and HIDEMs when derived from human ES or human iPS cells respectively.

\section{Expansion of HEDEMs/HIDEMs}


HEDEMs/HIDEMs, the end product of this protocol, are cultured as skeletal muscle-derived mesoangioblasts ${ }^{35}$ and have the advantage of a robust expansion potential (Figure 3 ) before undergoing terminal differentiation, a key advantage over most tissue-derived adult progenitors. Cells are expanded on normal cell culture plastic without any coating in a MegaCell-based medium supplemented with nutrients and basic fibroblast growth factor (bFGF; see Reagents Setup for detailed medium composition). Alternatively, cells can also be grown using an Iscove Modified Dulbecco's Medium (IMDM) supplemented as per Reagents List and Setup. Frozen stocks can be cryopreserved for short-term storage at $-80^{\circ} \mathrm{C}$ or in liquid nitrogen tanks, where they remain viable for at least 4 years after freezing.

\section{Characterisation of HEDEMs/HIDEMs}

Specific assays are required to evaluate the quality of the derived HEDEM/HIDEM populations in terms of their immunophenotype and safety profile.

\section{Analysis of surface markers by flow cytometry}

Human ES/iPS cell differentiation with this protocol yields relatively homogeneous populations of mesoangioblast-like cells. For this reason we have not performed any prospective isolation so far. On the other hand, a retrospective characterisation of the cells is required to ensure that the desired cell population was obtained. This can be done by flow cytometry analysis once the culture is stabilised. Specifically, the markers routinely assessed are the following: CD13, CD31, CD56, CD44, CD45, CD49b, CD146, alkaline phosphatase (AP) and stage-specific embryonic marker 4 (SSEA4) (Figure 4). Briefly, CD146 (a vascular/perivascular marker in vivo), CD13, CD44 and CD49b expression is usually high (above 50\%). CD56 (myoblast marker), CD45 (pan haematopoietic marker) and CD31 (endothelial cell marker) are very low or negative. AP detection via flow cytometry is not ideal as the antibody limits its detection to the membrane isoform. For this reason AP expression ranges from dim to very low. It 
is anyway important to detect at least one of the two markers CD146 and AP. When AP signal is not detectable via flow cytometric analysis, we advise to perform an enzymatic reaction in order to detect its activity (Supplementary Figure 1b). SSEA4, a pluripotency associated marker, has to be negative or low. If cell preparations display more than $10 \%$ of positivity for SSEA4 it is of critical importance to perform analysis on residual retention of pluripotency by immunofluorescence analysis or quantitative real time PCR (as shown $\mathrm{in}^{11}$ ) and an in vivo tumorigenic assay. HIDEMs and human mesoangioblasts have also been shown to be positive for CD73 and CD105 ${ }^{15}$, although we do not routinely assess expression of these two markers in our studies. For representative results on HIDEMs, feeder-free HIDEMs and HEDEMs please refer to Figure 4.

\section{Assessment of residual expression of pluripotency markers}

Even though assessment of surface markers by flow cytometry already provides indications on the possible presence of undifferentiated cells, it is good practice to assess HEDEMs/HIDEMs for any residual expression of pluripotency markers. This can be done using different techniques, such as immunofluorescence analysis (detailed in step 63-74 and shown in Supplementary Figure 1a) or quantitative real-time PCR (as shown in our previous paper ${ }^{11}$ ) for Oct4, Nanog, Sox2 and KIf4. HEDEMs/HIDEMs are expected to have very low or no expression of Oct4, Nanog, Sox2 and Klf4. All the analyses should be carried out comparing the expression of the above genes/proteins in HEDEMs/HIDEMs vs the parental ES/iPS cell lines. It is also useful to test by quantitative real-time PCR the expression of the exogenous pluripotency transgenes when integrating vectors are used to establish the initial iPS cell population (as shown in ${ }^{11}$ ).

\section{Induction of myogenic differentiation via MyoD activation}

Microarray gene expression profile of HIDEMs highlighted a remarkable similarity between them and skeletal-muscle derived mesoangioblasts. However, the same analysis also revealed that, at variance with their tissue-derived counterpart, they did not express key genes of the myogenic programme such as MyoD (Figure 
S2B in $^{16}$ ). Indeed, HEDEMs/HIDEMs are not capable of spontaneous skeletal myogenesis, although their potential to fuse with myotubes can be triggered upon co-culture with myogenic cells ${ }^{11}$. Moreover, previous work from our laboratory has shown that lentiviral-mediated expression of MyoD activates the myogenic programme in mesoangioblasts without erasing their ability to cross the vessel wall upon intra-arterial delivery and to contribute to the satellite cell pool. ${ }^{8}$.

Therefore HIDEMs/HEDEMs were transduced with a lentiviral vector encoding MyoD cDNA fused with the estrogen receptor (MyoD-ER $(T)^{36}$ ), thus allowing inducible nuclear translocation of the protein from the cytoplasm upon Tamoxifen administration (in vitro and/or in vivo). Using this strategy we have reproducibly observed very efficient myogenic differentiation, with an efficiency of up to $90 \%$ with just two $4 \mathrm{OH}$-Tamoxifen pulses in vitro. Importantly, cells with an integrated MyoD-ER(T) transgene but not exposed to Tamoxifen (i.e. having an inactive MyoD cytoplasmic protein) retain a good proliferation capacity, although moderately reduced compared with the parental cell line and can be expanded in culture (Figure 3). Upon Tamoxifen administration, MyoD-ER(T)HEDEMs/HIDEMs undergo robust and synchronous myogenic differentiation. Evaluation of the expression of myogenic differentiation markers such as myosin heavy chain $(\mathrm{MyHC})$ by immunofluorescence staining allows assessing the differentiation efficiency as the percentage of nuclei inside MyHC-positive cells versus the total number of nuclei (Figure 5). Notably, the possible future use of Tamoxifen in vivo in cell therapy protocols based upon HIDEMs or MyoD-ER(T) will also be facilitated by its beneficial effect as a drug for $\mathrm{DMD}^{37}$.

\section{Safety profile of pluripotent stem cell-derived myogenic cells}

Now that iPS cells have entered clinical experimentation ${ }^{38,39}$, screening the preclinical safety profile of ES/iPS-derived cells is particularly relevant. This analysis must include an assay to exclude the possibility to have a medicinal product harbouring tumorigenic properties. Prior to such a test, quality controls to evaluate genome stability of the HEDEM/HIDEM cell lines are advisable after completion of the commitment protocol. This can be done by karyotype analysis ${ }^{11}$ 
or by means of novel technologies such as array comparative genome hybridization ${ }^{40}$.

To rule out the risk of in vivo tumorigenesis, HEDEMs/HIDEMs are injected subcutaneously in immunodeficient animals. It is advisable to use a minimum of 5 immunodeficient mice and a consistent positive control (e.g. HeLa cells) for each cell population tested. This assay is performed only for cell lines that provided satisfactory results during all the derivation and differentiation. Please note that all the work must be carried under an appropriate animal licence and the guidelines for tumorigenic assays might vary between different regulatory institutions. We advise to follow the "Guidelines for the welfare and use of animals in cancer research" ${ }^{41}$. As this is an assay based upon a xenogeneic transplant, it is normally carried over a period of at least 4 months of follow-up post-procedure, during which time animals are examined at least once a week. If the assay is negative (i.e. no tumour formation), the cell line can be considered safe for in vivo applications. Overall, we have tested 9 human pluripotent stem cell-derived cell lines in vivo and no tumour formation was observed (follow up $\geq$ 4 months). Importantly, we have also compared HEDEMs (that are by definition transgene-free) and MyoD-ER(T)-HEDEMs, which only contain the integrated MyoD-ER(T) to exclude any possible transformation event due to insertional mutagenesis. We observed no tumour formation in both conditions.

\section{Level of expertise needed to implement the protocol}

The minimum skills required to implement this protocol include cell culture experience with human pluripotent, adherent and myogenic cells. We advise to outsource the production of the MyoD-ER(T) lentiviral vector if viral production is a technique not fully mastered in your laboratory. For the characterisation of the final product (HEDEMs/HIDEMs) it is required to be familiar with basic fluorescence microscopy and with fluorescence activated cell-sorting analyses. For the in vivo tumorigenic assay, approval of a specific animal licence needs to be in place before starting the procedure. Assessment of regenerative potential 
can be performed by transplantation of the final cell product in mouse models of muscle regeneration, as we recently detailed in a specific video-protocol ${ }^{14}$.

\section{Limitations of the protocol}

Despite the high efficiency and reproducibility of our protocol in generating myogenic cells from human pluripotent cells, there might be some limitations to its use. Firstly, to induce myogenic differentiation we use an integrating lentiviral vector harbouring a cassette encoding for MyoD-ER(T). Based upon previously published transplantation experiments in immune-competent dystrophic mice using the same MyoD-ER(T) construct $^{36}$, we do not have reasons to believe that the resulting fusion protein could be immunogenic for the host. Ad hoc immunological studies to address this issue might be necessary to translate this technology to the clinic. Although integrating vectors that overexpress myogenic factors in pluripotent or progenitor cells have been used also in other published protocols (e.g. ${ }^{20}$ ), safety concerns could arise due to their integrating nature. However, the potential risk of insertional oncogenesis has been drastically reduced with third generation self-inactivating lentiviral vectors ${ }^{42}$, which so far show excellent clinical safety profile ${ }^{43,44}$. Nevertheless, the risk of insertional mutagenesis must not be ignored. In this direction, it will be possible to screen transgene insertion with ad hoc vector integration analyses, leading to the identification of clones with so-called 'safe harbour' integrations ${ }^{43}$. As an alternative strategy, we are currently investigating the use of integration-free platforms such as integration-deficient lentiviral vectors ${ }^{45,46}$ or MyoD-mRNAs (commercially available, Stemgent cat. no. 05-0029). Another promising nonintegrating vector to deliver MyoD-ER currently under development in our laboratory consists in the transfer of an engineered human artificial chromosome $\left(\mathrm{HAC}^{47}\right)$ containing both MyoD and therapeutic genes (e.g. dystrophin in the case of Duchenne muscular dystrophy ${ }^{48}$; Hoshiya $\mathrm{H}$. et al, unpublished data).

Secondly, it is also important to consider that this method generates muscle cells without necessarily recapitulating skeletal muscle development in the embryo. Hence the application of this protocol might not be suitable for 
research on specific developmental aspects of skeletal muscle. Although this aspect is not of primary importance for drug screening platforms (where efficiency of differentiation is likely to be still one of the key eligibility criteria for a protocol), future upgrades of this methodology will focus towards a complete chemically-defined, animal-component- and transgene-free protocol (e.g. replacement of Matrigel and integrating viral vectors).

\section{MATERIALS}

\section{Reagents}

- Human pluripotent cells: healthy donor and dystrophic feeder-dependent human iPS cells described in ${ }^{11}$; Shef 6 human ES cells ${ }^{27}$; feeder-free SBI iPSCs (System Biosciences, USA \#SC102A-1N)

- Dulbecco's Modified Eagle's medium (DMEM) (Sigma, cat. no. D5671)

- MegaCell DMEM (Sigma, cat. no. M3942)

- Mimimum Essential Medium alpha (MEM a), Nucleosides (Life Technologies, cat. no. 22571-020)

- KO DMEM (Life Technologies, cat. no. 10829-018)

- DMEM F12 (Gibco, cat. no. 11039-21)

- Iscove's Modified Dulbecco's Medium (IMDM) (Sigma, cat. no. I3390)

- Collagenase IV (Sigma, cat. no. 5138)

- Essential 8 medium kit (Life Technologies, cat. no. A1517001)

- Horse serum (Euroclone, cat. no. ECS0090L)

- Foetal Bovine Serum (Life Technologies, cat. no. 10270-106)

- CRITICAL: we encountered batch-to-batch variability, which could greatly affect cell proliferation. Although different sera should be tested and compared to find the most appropriate, extremely from low to absent levels of endotoxins are good indicators of high quality serum. 
- Knockout Serum Replacement (Gibco, cat. No. 10828-028)

- PBS Calcium/Magnesium free (Gibco, cat. no. 10010-015)

- PBS tablets (Sigma, cat. no. P4417)

- L-Glutamine (Sigma, cat. no. G7513)

- Penicillin/Streptomycin (Sigma, cat. no. P0781)

- 2-Mercaptoethanol (Gibco, cat. no. 31350-010)

- Non-essential amino acid solution (Sigma, cat. no. M7145)

- Human bFGF (Gibco, cat. no. AA 10-155)

- Insulin-transferrin-selenium (ITS) (Gibco, cat. no. 51500-056)

- Oleic acid (Sigma, cat. no. 01257-10MG)

- Linoleic acid (Sigma, cat. no. L5900-10MG)

- Iron Sulfate (e.g. Ferinsol, Mead Johnson as detailed in reagents setup; alternatively use Iron [II] cloride tetrahydrate from Sigma, cat no. 44939)

- Sodium Ferric Gluconate Complex (e.g. Ferlixit, Aventis as detailed in reagents setup; alternatively use Iron [III] nitrate nonahydrate from Sigma, cat no. 254223)

- Rock inhibitor Y27362 (Calbiochem, cat. no. 688000)

- Grow factors-reduced Matrigel LDEV-Free (Corning, cat. no. 356231)

- Geltrex LDEV-Free, hESC-qualified, reduced growth factor basement membrane matrix (Life Technologies, cat. no. A1413301)

- EmbryoMax 0.1\% (wt/vol) Gelatin Solution (Merk Millipore, cat. no. ES006-B)

- Trypsin (Sigma, cat. no. T3924)

- $0.5 \mathrm{M}$ EDTA, pH 8.0 (Fisher Scientific, cat. no. 10182903)

- Paraformaldehyde (TAAB, cat. no. P001)

- CAUTION: paraformaldehyde is extremely toxic and must be handled with adequate personal protective equipment under a chemical cabinet.

- 4-OH Tamoxifen (Sigma, cat. no. H7904)

- pLv-CMV-MyoD-ER(T) vector (Addgene, cat. no. 26809) 
- MyoD-ER(T) integrating lentiviral vector carrying the pLv-CMV-MyoD$\mathrm{ER}(\mathrm{T})$ plasmid

- CAUTION: production and work with viral vectors need to be carefully performed under appropriate regulation and must be done in dedicated facilities. If you are not allowed to produce viral vectors in your laboratory please refer to an authorised facility. If you are allowed to produce lentiviral vectors, the following protocol can be used as a reference ${ }^{49}$.

- Bovine serum albumin (Sigma, cat. no. A7906)

- Triton X-100 (Sigma, cat. no. T8787)

- Donkey serum (Sigma, cat. no. D9663)

- Donkey anti-Mouse lgG (H+L) 546 (Molecular probes, cat. no. A10036)

- Donkey anti-Rabbit IgG (H+L) 488 (Molecular probes A21206)

- Sterile cell culture grade water (Gibco, cat. no. 15230-089)

- DMSO (Thermo scientific, cat. no. TS20684)

- Isopropanol 99.5+\% (Acros organic, cat. no. 389710025)

- Ethanol (Acros organic, cat. no. 615095000)

- Trypan blue (Sigma, cat. no. T8154)

- Fluorescence mounting medium (Dako, cat. no. S3023)

- Mouse anti SSEA 4, PE conjugated (BD Biosciences, cat. no. 560128)

- Hoechst 33342 (Molecular probes, cat. no. H21492)

- Mouse anti Myosin Heavy Chain antibody (Dilute 1:2; DSHB, cat. no. MF20)

- Mouse anti Oct3/4 (Santacruz, cat. no. sc5279)

- Rabbit anti Nanog (Abcam, cat. no. ab80892)

- Rabbit anti Sox2 (Abcam, cat. no. ab97959)

- Mouse anti human CD44, FITC (BD Biosciences, cat. no. 560977)

- Mouse anti human CD56, APC (BioLegend, cat. no. 304610)

- Mouse anti human CD31, FITC (Immunostep, cat. no. 31F-100T)

- Mouse anti human CD13, FITC (ID Labs inc, cat. no. IDAC1071) 
- Mouse anti human CD49b, FITC (BD Biosciences, cat. no. 555498)

- Mouse anti human CD146, PE (Biocytex, cat. no. 5050-PE100T)

- Mouse anti human CD45, PE (BD Biosciences, cat. no. 5555483)

- Mouse anti human alkaline phosphatase, FITC (Santa Cruz, cat. no. 217084)

- Mouse anti human CD44, FITC (BD Biosciences, cat. no. 553133)

- NBT/BCIP Stock Solution (Roche, cat. no.11681451001)

- Trizma hydrochloride (Sigma, cat. no. T5941)

- $\mathrm{NaCl}$ (Sigma, cat. no. S3014)

- $\mathrm{MgCl}_{2}$ (Sigma, cat. no. M8266)

- Tween 20 (Sigma, cat. no. P9416)

- Immunodeficient adult mice (e.g., scid/beige, NOD or NSG strains) from an authorised facility and kept in a specific pathogen-free environment

- CAUTION: any experiment involving animal work must be carried in accordance to specific regulations that vary across countries and institutions. Once the authorisation for animal work is granted, we advise to follow the "Guidelines for the welfare and use of animals in cancer research"41.

\section{Equipment}

- Cell culture 6-well plates (Nunc, cat. no. 140675)

- Cell culture 12-well plates (Nunc, cat. no. 150628)

- Cell culture T25 flask (Nunc, cat. no. 156367)

- Cell culture T75 flask (Nunc, cat. no. 156499)

- $35 \mathrm{~mm} \times 10 \mathrm{~mm}$ cell culture dishes (Nunc, cat. no. 153066)

- Cryovials (Corning, cat. no. 430488)

- Cell counting slides with grids (Hycor, cat. no. 87144)

- 30mm coverslips (Arlenfeld, cat. no. 0111700)

- Sterile cell scrapers (Corning, cat. no. 3010)

- Sterile $15 \mathrm{ml}$ plastic tubes (Greiner Bio-one, cat. no.188271) 
- Sterile $50 \mathrm{ml}$ plastic tubes (Greiner Bio-one, cat. no.227261)

- FACS tubes (BD Falcon, cat. no. 352063)

- Sterile plastic pipettes (Corning, cat. no. 4486 / 4487 / 4488 / 4489)

- Filtered tips (Corning, cat. no. 4810 / 4821 / 4823 /4809)

- Pipettman (BD Falcon, cat. no. 357589)

- Pipettes (Gilson, cat. no. F167300)

- Centrifuge (Sigma, cat. no. 10360)

- Cell incubator, $5 \% \mathrm{CO}_{2} 3-5 \% \mathrm{O}_{2}$ (New Brunswick Scientific, cat. no. Galaxy 170R)

- Phase contrast inverted microscope (Leica, cat. no. DMIL LED)

- Fluorescence microscope (Leica, cat. no. DMI 6000B)

- Flow cytometer (Beckman Coulter, CyAn ADP Analyzer)

- Mister frosty freezing container (Nalgene, cat. no. 5100-0001)

- $-80^{\circ} \mathrm{C}$ freezer (New Brunswick Scientific, cat. no. U410-HEF)

- Liquid nitrogen storage tank (Taylor Wharton, cat. no. LS6000)

- $0.5 \mathrm{ml}$ syringes for subcutaneous injection (BD, cat. no. 320927)

- Vacuum filtering units (Corning, cat. no. 431097)

- $40 \mu \mathrm{m}$ cell strainer (Falcon, cat. no. 352340)

- $500 \mathrm{~mL} 0.22 \mu \mathrm{m}$ pore vacuum filters (cat. no. Corning 431097 ) 


\section{Reagents setup}

- Human bFGF: resuspend powder in sterile cell culture grade water at a final concentration of $100 \mathrm{ng} / \mu \mathrm{l}$. Aliquot and store at $-20^{\circ} \mathrm{C}$.

- Rock inhibitor Y27362: resuspend powder at a final concentration of $1 \mathrm{mg} / \mathrm{ml}$. Aliquot and store at $-20^{\circ} \mathrm{C}$. Use diluted 1:300 in medium.

- Matrigel: thaw the stock solution overnight on ice at $4^{\circ} \mathrm{C}$ and once liquid keep on ice and aliquot using cold tips and cold tubes. Store at $-20^{\circ} \mathrm{C}$. When needed, thaw on ice and dilute 1:100 in DMEM.

- Geltrex: thaw the stock solution overnight on ice at $4^{\circ} \mathrm{C}$ and once liquid keep on ice and aliquot using cold tips and cold tubes. Store at $-20^{\circ} \mathrm{C}$. When needed, thaw on ice and dilute 1:100 in DMEM F12.

- Iron Sulfate: stock solution is provided at $12.5 \mathrm{mg} / \mathrm{ml}$ (wt / vol). Dilute 1:1000 in sterile water and use $530 \mu \mathrm{l} / \mathrm{l}$.

- Sodium Ferric Gluconate: stock solution is provided at $25 \mathrm{mg} / \mathrm{ml}$ (wt / vol). Dilute 1:1000 in sterile water and use $3.3 \mathrm{ml} / \mathrm{l}$.

- Oleic acid: prepare a stock solution dissolving the powder in sterile water at a concentration of $23.5 \mathrm{mg} / \mathrm{ml}$ (wt / vol), which is equal to $2.5 \mathrm{mM}$. Aliquot and store at $-20^{\circ} \mathrm{C}$. Use at the final concentration of $0.5 \mu \mathrm{M}$ in medium.

- Linoleic acid: prepare a stock solution dissolving the powder in sterile water at a concentration of $23 \mathrm{mg} / \mathrm{ml}$ ( $w t / \mathrm{vol}$ ), which is equal to $2.5 \mathrm{mM}$. Aliquot and store at $-20^{\circ} \mathrm{C}$. Use at the final concentration of $0.5 \mu \mathrm{M}$ in medium.

- iPS cell medium

- KO DMEM

- $25 \%$ ( $\mathrm{vol} / \mathrm{vol}) \mathrm{KSR}$

- $1 \%$ (vol / vol) Non essential amino acids

- $2 \mathrm{mM}$ glutamine

- $100 \mathrm{IU} \mathrm{ml} \mathrm{penicillin}$

- $100 \mathrm{mg} / \mathrm{ml}$ streptomycin

○ $0.1 \mathrm{mM}$ 2-Mercaptoethanol 
- $10 \mathrm{ng} / \mathrm{ml}$ human bFGF

Filter complete medium with $0.22 \mu \mathrm{m}$ pore vacuum filters

- ES cell medium

- KO DMEM

○ $20 \%$ (vol / vol) KSR

- $1 \%$ (vol / vol) Non essential amino acids

- $1 \mathrm{mM}$ glutamine

- $0.1 \mathrm{mM}$ 2-Mercaptoethanol

- $4 \mathrm{ng} / \mathrm{ml}$ human bFGF

Filter complete medium with $0.22 \mu \mathrm{m}$ pore vacuum filters.

- Feeder-free iPS cell medium

- Essential 8 basal medium

- $1 \%$ (vol / vol) Essential 8 supplement

Filter complete medium with $0.22 \mu \mathrm{m}$ pore vacuum filters.

- Dissociation medium

○ $0.5 \mathrm{mM}$ EDTA

- $1 \%$ ( $\mathrm{vol} / \mathrm{vol})$ FBS

○ $0.1 \mathrm{mM}$ 2-Mercaptoethanol

- PBS Calcium/Magnesium free

Filter complete medium with $0.22 \mu \mathrm{m}$ pore vacuum filters.

- Commitment medium

- MEM a, Nucleosides

○ $10 \%$ (vol / vol) FBS

- $2 \mathrm{mM}$ glutamine

- $100 \mathrm{lU} / \mathrm{ml}$ penicillin

- $100 \mathrm{mg} / \mathrm{ml}$ streptomycin

○ $0.1 \mathrm{mM}$ 2-Mercaptoethanol

Filter complete medium with $0.22 \mu \mathrm{m}$ pore vacuum filters.

- Proliferation medium

- MegaCell DMEM

○ $5 \%$ ( $\mathrm{vol} / \mathrm{vol})$ FBS 
- $100 \mathrm{lU} / \mathrm{ml}$ penicillin

○ $100 \mathrm{mg} / \mathrm{ml}$ streptomycin

- $2 \mathrm{mM}$ glutamine

- $1 \%$ (vol / vol) Non-essential amino acids

- $0.05 \mathrm{mM}$ 2-Mercaptoethanol

- $5 \mathrm{ng} / \mathrm{ml}$ human bFGF

Filter complete medium with $0.22 \mu \mathrm{m}$ pore vacuum filters.

- Alternative Proliferation medium (in case MegaCell DMEM is not available in your country or out of stock)

- IMDM

○ $10 \%$ (vol / vol) FBS

- $100 \mathrm{lU} / \mathrm{ml}$ penicillin

○ $100 \mathrm{mg} / \mathrm{ml}$ streptomycin

- $2 \mathrm{mM}$ glutamine

- $1 \%$ (vol / vol) Non-essential amino acids

- $0.05 \mathrm{mM}$ 2-Mercaptoethanol

- $5 \mathrm{ng} / \mathrm{ml}$ human bFGF

○ $0.5 \mu \mathrm{M}$ Oleic Acid

○ $0.5 \mu \mathrm{M}$ Linoleic Acid

- $82.5 \mu \mathrm{g} / \mathrm{L}$ (wt / vol) Iron Sulfate

○ $6.625 \mu \mathrm{g} / \mathrm{L}$ (wt / vol) Sodium Ferric Gluconate

Filter complete medium with $0.22 \mu \mathrm{m}$ pore vacuum filters.

- Differentiation medium

- DMEM

- $2 \%$ (vol / vol) Horse Serum

- $100 \mathrm{lU} / \mathrm{ml}$ penicillin

○ $100 \mathrm{mg} / \mathrm{ml}$ streptomycin

- $2 \mathrm{mM}$ glutamine

Filter complete medium with $0.22 \mu \mathrm{m}$ pore vacuum filters.

- Freezing medium

- $90 \%$ (vol / vol) FBS 
- $10 \%$ (vol / vol) DMSO

Filter complete medium with $0.22 \mu \mathrm{m}$ pore vacuum filters.

- Fluorescence activated cell sorting (FACS) buffer

- PBS

- $1 \%$ ( $\mathrm{vol} / \mathrm{vol}) \mathrm{FBS}$

- $0.2 \mathrm{mM}$ EDTA

- 4-OH Tamoxifen: dissolve powder in ethanol at a stock concentration of $25 \mathrm{mM}$ and store at $-20^{\circ} \mathrm{C}$. Prior to use thaw an aliquot, dilute it to $250 \mu \mathrm{M}$ with PBS and then dilute it 1:250 in fresh Differentiation Medium.

- Collagenase IV: dissolve collagenase in KO DMEM at a final concentration of $1 \mathrm{mg} / \mathrm{ml}$. Aliquot and store at $-20^{\circ} \mathrm{C}$.

- $4 \%$ (wt/vol) paraformaldehyde solution: dissolve $4 \mathrm{~g}$ of paraformaldehyde into $100 \mathrm{ml}$ of PBS. Stir on the hot plate allowing the solution to warm up to $60^{\circ} \mathrm{C}$. Adjust the $\mathrm{pH}$ to 7.4 by adding $1 \mathrm{~N} \mathrm{NaOH}$ dropwise and wait until the solution is completely clear. Adjust the final volume with double distilled water. Aliquot and store at $-20^{\circ} \mathrm{C}$. Once thawed, working aliquots can be stored at $4^{\circ} \mathrm{C}$ for a week.

- CAUTION: paraformaldehyde is extremely toxic and must be handled with adequate personal protective equipment under a chemical cabinet.

- $2 \%(\mathrm{wt} / \mathrm{vol})$ paraformaldehyde solution: Dilute $1: 2$ a required volume of $4 \%$ (wt/vol) paraformaldehyde solution with PBS. Aliquot and store at $-20^{\circ} \mathrm{C}$. Once thawed, working aliquots can be stored at $4^{\circ} \mathrm{C}$ for a week.

- CAUTION: paraformaldehyde is extremely toxic and must be handled with adequate personal protective equipment under a chemical cabinet.

- Phosphate buffered saline (PBS) for immunofluorescence: dissolve one tablet of PBS in $200 \mathrm{ml}$ of double distilled water. Stir until completely dissolved. 
- Permeabilisation buffer for immunofluorescence $(0.2 \%$ vol/vol Triton - $1 \%$ $\mathrm{wt} / \mathrm{vol} \mathrm{BSA}$ ): dissolve $1 \mathrm{~g}$ of BSA in $100 \mathrm{ml}$ of PBS and stir well until dissolved. Add $200 \mu \mathrm{l}$ of Triton and mix until dissolved. Store at $4^{\circ} \mathrm{C}$.

- Blocking buffer for immunofluorescence (10\% vol/vol animal serum): dilute $100 \mu \mathrm{l}$ of animal serum in $900 \mu \mathrm{l}$ of PBS (final volume $1 \mathrm{ml}$ ).

- Animal serum for immunofluorescence: thaw at $4^{\circ} \mathrm{C}$, aliquot and store at $20^{\circ} \mathrm{C}$.

- Hoechst 33342: dissolve the dye in water at a final concentration of 10 $\mathrm{mg} / \mathrm{ml}$, aliquot and store protected from light at $4^{\circ} \mathrm{C}$. Use diluted 1:250.

- Polybrene: Prepare a stock solution of $8 \mathrm{mg} / \mathrm{ml}$ by dissolving the required amount of powder in sterile water or PBS. Store solution protected from light at $4^{\circ} \mathrm{C}$. Use at $1: 1000$ dilution in Proliferation Medium when transducing cells.

- Trizma hydrochloride $1 \mathrm{M}$ : dissolve $15.76 \mathrm{~g}$ in $100 \mathrm{ml}$ of double distilled water and adjust the $\mathrm{pH}$ to 5.5. Store at room temperature (our laboratory has an average room temperature of $20 \pm 2^{\circ} \mathrm{C}$ ).

- $\mathrm{NaCl} 1 \mathrm{M}$ : dissolve $5.49 \mathrm{~g}$ in $100 \mathrm{ml}$ of double distilled water. Store at room temperature.

- $\mathrm{MgCl}_{2} 1 \mathrm{M}$ : dissolve $9.52 \mathrm{~g}$ in $100 \mathrm{ml}$ of double distilled water. Store at room temperature for maximum 1 month.

- CAUTION: the reaction is exothermic: use a large container when dissolving powder to avoid spilling of the solution.

- Tween 20 20\% ( $\mathrm{vol} / \mathrm{vol}$ ): dissolve $2 \mathrm{ml}$ of Tween $20 \mathrm{in} 18 \mathrm{ml}$ of double distilled water. Store at room temperature in a glass container.

- Alkaline phosphatase staining solution: for each $35 \mathrm{~mm}$ dish to be stained for alkaline phosphatase via enzymatic reaction, prepare $1 \mathrm{ml}$ of staining solution by mixing $100 \mu \mathrm{l}$ of Trizma hydrochloride $1 \mathrm{M}, 100 \mu \mathrm{l}$ of $\mathrm{NaCl} 1 \mathrm{M}$, $50 \mu \mathrm{l}$ of $\mathrm{MgCl}_{2} 1 \mathrm{M}, 5 \mu \mathrm{l}$ Tween $2020 \%$ ( $\mathrm{vol} / \mathrm{vol}$ ), $725 \mu \mathrm{l}$ of double distilled water and $20 \mu \mathrm{l}$ of NBT/BCIP stock solution. Prepare a fresh solution for each staining.

- CAUTION: the solution is light sensitive. 


\begin{tabular}{|l|l|l|}
\hline Antibody & Working dilution & Example of positive control \\
\hline Anti Oct4 & $1: 100$ & Human iPS/ES cells \\
\hline Anti Sox2 & $1: 200$ & Human iPS/ES cells \\
Anti Nanog & $1: 100$ & Human iPS/ES cells \\
Anti SSEA4 & $1: 25$ & Human iPS/ES cells \\
Anti CD44 & $1: 100$ & Human leucocytes \\
Anti CD56 & $1: 50$ & Human myoblasts \\
Anti CD31 & $1: 125$ & HUVEC \\
Anti CD13 & $1: 125$ & HUVEC \\
Anti CD49b & $1: 25$ & Human lymphocytes \\
Anti CD146 & $1: 10$ & HUVEC \\
Anti CD45 & $1: 25$ & Human leucocytes \\
Anti alkaline phosphatase & $1: 100$ & HeLa cells \\
Anti myosin heavy chain & $1: 2$ & Differentiated myoblasts \\
\hline
\end{tabular}

Table 1. Working dilutions of antibodies and possible positive controls. 


\section{Equipment setup}

- Matrigel-coated plates: thaw an aliquot of Matrigel on ice and once liquefied, dilute it 1:100 in ice-cold DMEM with a cold pipette tip. Mix throughout and put $1 \mathrm{ml}$ of diluted Matrigel solution in each $35 \mathrm{~mm}$ dish or well of a 6-well plate. Shake the plate gently in order to cover the whole surface with Matrigel. Incubate at $37^{\circ} \mathrm{C}$ for 30 minutes and then remove the residual Matrigel without scraping the bottom of the well. Wash twice with DMEM or PBS. For immediate use, plate cells in the appropriate medium. For later use, cover the well with $1 \mathrm{ml}$ of DMEM and put back in the incubator at $37^{\circ} \mathrm{C}$. Coated plates should be used on the day of preparation.

- CRITICAL STEP: undiluted Matrigel solidifies above $4^{\circ} \mathrm{C}$. It is therefore important to thaw it on ice and dilute it in ice-cold medium with a cold pipette tip.

- Geltrex-coated plates: thaw an aliquot of Geltrex on ice and once liquefied, dilute it 1:100 in ice-cold DMEM F12 with a cold pipette tip. Mix throughout and put $1 \mathrm{ml}$ of diluted Geltrex solution in each $35 \mathrm{~mm}$ dish or well of a 6-well plate. Shake the plate gently in order to cover the whole surface with Geltrex. Incubate at $37^{\circ} \mathrm{C}$ for 60 minutes and then remove Geltrex without scraping the bottom of the well. For immediate use, plate cells in the appropriate medium. For later use, wrap with Parafilm and store at $4^{\circ} \mathrm{C}$ for up to two weeks.

- CRITICAL STEP: undiluted Geltrex solidifies above $4^{\circ} \mathrm{C}$. It is therefore important to thaw it on ice and dilute it in ice-cold medium with a cold pipette tip.

- Gelatin-coated plates: add $1.5 \mathrm{ml}$ of EmbryoMax $0.1 \%$ (wt/vol) Gelatin solution to each well of a 6-well plate and incubate at room temperature for 30 minutes. Discard solution and immediately add cells resuspended in medium. 


\section{PROCEDURE}

\section{Steps 1-40: From pluripotent cells to mesoangioblast-like cells}

\section{Timing: 18-21 days}

Single cell dissociation of pluripotent cell colonies and early commitment

1 For a successful outcome, ES/iPS cell cultures must be homogeneous with no differentiated cells contaminating the dish. Start the protocol when the colonies population are at a confluency of about $70 \%$, ideally with 1-3 wells of a 6-well plate.

- CRITICAL STEP: if a minimal proportion of differentiated cells is present in the culture, they need to be manually selected and removed prior to the start of the differentiation procedure.

2 In order to increase single-cell survival after dissociation, pre-treat ES/iPS cells with $10 \mathrm{mM}$ ROCK inhibitor adding it to the cell culture medium. Incubate for 1 hour at $37^{\circ} \mathrm{C}$.

3 Prepare a $35 \mathrm{~mm}$ dish coated with $1 \%$ vol / vol growth factor-reduced Matrigel as described in the Equipment setup.

4 Remove the medium with ROCK inhibitor from the plates and gently wash the ES/iPS cells with $2 \mathrm{ml} \mathrm{Ca}{ }^{2+}-\mathrm{Mg}^{2+}$-free PBS.

5 Add $1 \mathrm{ml}$ of pre-warmed Dissociation Medium to each ES/iPS cell well and incubate at $37^{\circ} \mathrm{C}$ for 10 minutes.

6 Shake plates gently by tapping on their side in order to facilitate dissociation of colonies. Inspect the plates and look for floating cells.

A. Feeder-dependent cultures: aim to detach most of the colonies at the expense of feeder cells, which will remain attached to the plastic. The first incubation is usually not enough to detach all the cells so put the plates back in the incubator and repeat step 6 every 15 minutes for up to 2 hours. Move to the next step when most of the colonies detached as single cells or little clumps. 
- CRITICAL STEP: do not keep the cells in Dissociation Medium for more than 2 hours total as this decreases cell survival and compromises the following steps of the protocol.

B. Feeder-free cultures: iPS cells cultured in feeder-free condition detach very easily from the dish after 15 minutes of incubation at $37^{\circ} \mathrm{C}$. No further incubation should be required.

7 Collect Dissociation Medium with the detached cells in a $15 \mathrm{ml}$ sterile tube. Gently resuspend the cells with a P1000 tip to facilitate disaggregation of clumps.

- CRITICAL STEP: in case of feeder-dependent cultures, make sure not to scrape the bottom of the dish in order not to detach feeder cells.

8 Add at least 1 volume of pre-warmed Commitment Medium to the tubes to dilute Dissociation Medium.

9 Centrifuge cell suspension at $232 \mathrm{~g}$ for 5 minutes.

10 Discard supernatant, resuspend the pellet in pre-warmed Commitment Medium and count cells.

- CRITICAL STEP: in order to plate the appropriate number of cells, it is important to evaluate cell viability through a vital staining, such as Trypan blue.

11 Wash twice the Matrigel-coated dish with DMEM or PBS and plate cells according to option A (feeder-dependent cultures) or B (feeder-free cultures):

A. Feeder-dependent cultures: plate $6 \times 10^{4}$ cells $/ \mathrm{cm}^{2}$, which is approximately $6 \times 10^{5}$ cells for a $35 \mathrm{~mm}$ dish

? TROUBLESHOOTING

B. Feeder-free cultures: plate $3 \times 10^{5}$ cells $/ \mathrm{cm}^{2}$, which is approximately $3 \times$ $10^{6}$ cells for a $35 \mathrm{~mm}$ dish.

12 Incubate the plate at $37^{\circ} \mathrm{C}$ with $5 \% \mathrm{CO}_{2}$ and 3 to $5 \% \mathrm{O}_{2}$.

13 Replace Commitment Medium the next day in order to eliminate dead cells.

14 Inspect the plate daily and replace Commitment Medium every 2-3 days with pre-warmed fresh Commitment Medium.

15 Move to the following step after 1 week. 
Intermediate commitment and adaptation to a reduced cell density

16 Prepare a $35 \mathrm{~mm}$ dish coated with $1 \%$ vol / vol growth factor-reduced Matrigel as described in the Equipment setup.

17 Dissociate the cell culture with pre-warmed Dissociation Medium as detailed in points 3-6. Additional gentle scraping of the dish surface can be performed if cells do not detach completely after a maximum of 2 hours in Dissociation Medium.

\section{? TROUBLESHOOTING}

18 Collect the cells in Dissociation Medium in a $15 \mathrm{ml}$ tube and gently resuspend them with a P1000 tip. Add 1 volume of pre-warmed Commitment Medium.

19 Filter the cell suspension with a $40 \mu \mathrm{m}$ cell strainer placed on a collection tube in order to remove aggregates.

20 Centrifuge filtered cell suspension at $232 \mathrm{~g}$ for 5 minutes.

21 Discard the supernatant, resuspend the pellet in pre-warmed Commitment Medium and count cells.

- CRITICAL STEP: in order to plate the appropriate number of cells, it is important to evaluate cell viability through a vital staining, such as Trypan blue.

22 Wash twice the Matrigel-coated dish with DMEM or PBS and plate $2.5 \times 10^{4}$ cells $/ \mathrm{cm}^{2}$ (approximately $2.5 \times 10^{5}$ cells for a $35 \mathrm{~mm}$ dish).

\section{? TROUBLESHOOTING}

23 Incubate cells at $37^{\circ} \mathrm{C}$ with $5 \% \mathrm{CO}_{2}$ and 3 to $5 \% \mathrm{O}_{2}$.

24 Inspect the plate daily and replace Commitment Medium every other day with fresh pre-warmed medium.

? TROUBLESHOOTING

25 Move to the following step after 1 week. 
Late commitment: high-density culture and adaptation to trypsin dissociation

26 Prepare a $35 \mathrm{~mm}$ dish coated with 1\% (vol / vol) growth factor-reduced Matrigel as described in the Equipment setup.

27 Wash the plate with the cells with $2 \mathrm{ml} \mathrm{PBS}$ and add $0.5 \mathrm{ml}$ of trypsin to detach them. Incubate plates at $37^{\circ} \mathrm{C}$ with $5 \% \mathrm{CO}_{2}$ and 3 to $5 \% \mathrm{O}_{2}$ for 5 minutes.

28 Remove cells from the incubator and shake plate to facilitate cell detachment. Inspect under the microscope. When all the cells have detached, block trypsin activity with pre-warmed Commitment Medium. Resuspend with a pipette and collect the cell suspension.

29 Centrifuge cell suspension at $232 \mathrm{~g}$ for 5 minutes.

30 Discard supernatant, resuspend the pellet in pre-warmed Proliferation Medium and count cells.

- CRITICAL STEP: in order to plate the appropriate number of cells, it is important to evaluate cell viability through a vital staining, such as Trypan blue.

31 Wash twice the Matrigel-coated dish with DMEM or PBS and plate $2 \times 10^{4}$ cells $/ \mathrm{cm}^{2}$ (approximately $2 \times 10^{5}$ cells for a $35 \mathrm{~mm}$ dish or at confluence of $80 \%)$.

32 Incubate cells at $37^{\circ} \mathrm{C}$ with $5 \% \mathrm{CO}_{2}$ and 3 to $5 \% \mathrm{O}_{2}$.

33 Inspect cells daily and replace medium every other day.

34 Move to the next step after 3 days at 100\% confluence.

\section{HEDEM/HIDEM cultures stabilisation}

35 Detach cells by trypsinization as described in points 27-28.

36 Centrifuge cell suspension at $232 \mathrm{~g}$ for 5 minutes.

37 Discard the supernatant, resuspend the pellet in pre-warmed Proliferation Medium and count cells.

38 Plate $1.2 \times 10^{4}$ cells $/ \mathrm{cm}^{2}$ on cell culture plastic without any coating. 
39 Incubate cells at $37^{\circ} \mathrm{C}$ with $5 \% \mathrm{CO}_{2}$ and 3 to $5 \% \mathrm{O}_{2}$.

40 Inspect the cells daily and split the culture by trypsinisation as they reach $80 \%$ confluence. Different lines differ in proliferation rate but generally cultures require splitting every 3-4 days. The cell population at this step is regarded as HEDEMs/HIDEMs passage zero (p0). From now onwards, cells are cultured like bona fide mesoangioblasts ${ }^{35}$. The cells can now be expanded and cryopreserved.

\section{Step 41-44: Expansion of HEDEMs/HIDEMs}

\section{Timing: minimum 7-10 days (depending on the number of cells required)}

$41 \mathrm{HEDEM} / \mathrm{HIDEM}$ cultures require splitting when the culture is roughly $80 \%$ confluent. On the day of splitting, wash plates once with PBS, add a volume of trypsin necessary to cover the whole culture surface and incubate cells at $37^{\circ} \mathrm{C}$ for 5 minutes.

42 Shake plate to facilitate cell detachment and inspect them under the microscope. When all the cells are detached add pre-warmed Proliferation Medium to block trypsin activity. Resuspend and collect cells in a tube for centrifugation.

43 Centrifuge cell suspension at $232 \mathrm{~g}$ for 5 minutes.

44 Discard the supernatant, resuspend the pellet in pre-warmed Proliferation Medium and count cells. Plate $1.2 \times 10^{4}$ cells $/ \mathrm{cm}^{2}$. Cells generally require a splitting ratio of 1:3 - 1:6 depending on the cell line.

\section{Step 45-50: Cryopreservation of HEDEMs/HIDEMs}

\section{Timing: 1 hour}

From passage zero, HEDEMs/HIDEMs can be cryopreserved. It is highly recommended to cryopreserve a stock of cells at low passages ( $00-3)$ and, if possible, it is good practice to freeze one vial of cells or more at each passage.

45 Fill the lower chamber of a Nalgene freezing container with isopropanol and pre-chill the container at $4^{\circ} \mathrm{C}$.

46 When cell culture reaches $80 \%$ confluency, detach cells as detailed in points 41-43. 
47 Discard the supernatant and any residual medium left in the tube.

48 Disrupt the cell pellet by gentle tapping at the bottom of the tube.

49 Resuspend the pellet in $1 \mathrm{ml}$ of cold freezing medium, transfer to a labelled cryovial and immediately put vial in a freezing container.

50 Put freezing container at $-80^{\circ} \mathrm{C}$. For long-term storage, transfer vial in a liquid nitrogen storage tank.

\section{Step 51-73: Characterisation of HEDEMs/HIDEMs}

Timing: 1 day for FACS analysis, 1 day for immunofluorescence staining

After derivation, HEDEMs/HIDEMs should be characterised by flow cytometric analysis (51-61) to assess the expression of a panel of pericyte/mesoangioblast markers and by immunofluorescence to confirm the absence of any residual pluripotency marker (62-73).

Immunophenotype analysis by flow cytometry

51 Wash cells with PBS and add trypsin to detach them. Incubate plates at $37^{\circ} \mathrm{C}$ with $5 \% \mathrm{CO}_{2}$ and 3 to $5 \% \mathrm{O}_{2}$ for 5 minutes.

52 Remove cells from the incubator and shake plate to facilitate cell detachment. Inspect under the microscope. When all the cells have detached, block trypsin activity with FACS buffer. Resuspend with a pipette and collect the cell suspension.

53 Filter cells through a $40 \mu \mathrm{m}$ (pores' size) cell strainer and count them.

54 Place appropriate cell number in single centrifuge-proof FACS tubes. Usually at least $1 \times 10^{5}$ cells are used for each antibody staining and for unstained controls.

55 Centrifuge the tubes at $232 \mathrm{~g}$ for 5 minutes.

56 Discard supernatant, gently resuspend pellet in $2 \mathrm{ml}$ of FACS buffer for a wash and centrifuge at $232 \mathrm{~g}$ for 5 minutes.

57 Discard the supernatant and gently tap the cell pellet to resuspend it in $50 \mu \mathrm{l}$ of FACS buffer in the tube. 
58 Leave unstained control tubes on ice and set aside until FACS read. In parallel add staining antibodies to samples at the dilution described in the reagents list section and incubate at $4^{\circ} \mathrm{C}$ in the dark for 45 minutes.

59 Add $3 \mathrm{ml}$ of FACS buffer to samples to wash unbound antibody and centrifuge the tubes at $232 \mathrm{~g}$ for 5 minutes.

- PAUSE POINT: at this point you can either analyse samples immediately or you can fix them with $2 \%$ (wt / vol) paraformaldehyde, protecting them from light and storing them at $4^{\circ} \mathrm{C}$. Samples can be analysed up to three days later.

60 Discard supernatant and resuspend cells in the appropriate volume for analysis.

61 Perform FACS analysis.

- CRITICAL STEP: if you are not familiar with the FACS device ask facility operators for suggestions on laser and compensation settings, especially if you are working with genetically manipulated fluorescent cells (e.g. GFP-positive cells).

\section{Assessment of residual pluripotency markers}

62 Plate four $35 \mathrm{~mm}$ dishes with $1 \times 10^{5}$ HEDEMs/HIDEMs each in Proliferation Medium.

- CRITICAL STEP: it is important to have a dish of pluripotent cells from which HEDEMs/HIDEMs were derived to use as a positive control.

6324 hours after plating remove Proliferation Medium and wash twice with PBS.

64 Fix plates with $4 \%$ wt / vol paraformaldehyde for 10 minutes at RT

- CAUTION: Paraformaldehyde is extremely toxic and must be handled under a chemical cabinet.

- PAUSE POINT: fixed cells can be kept with PBS at $4^{\circ} \mathrm{C}$ for at least two weeks before proceeding with the staining.

65 Permeabilise cells with PBS $-0.2 \%$ vol / vol Triton - $1 \%$ wt / vol BSA for 30 minutes at room temperature. 
66 Remove permeabilising solution and incubate with $10 \%$ vol / vol animal serum for 30 minutes at room temperature to block non-specific binding sites.

67 Remove animal serum and incubate one dish with anti-Sox2, one with antiOct4 and one with anti-Nanog primary antibody for 1 hour at room temperature.

- CRITICAL STEP: we advise to use the remaining dish to assess potential non-specific binding of the secondary antibody to the sample and to evaluate an eventual level of background. This can be done by incubating the dish with just the secondary antibody and the nuclear dye.

68 Perform three washes of 5 minutes with PBS - $0.2 \%$ vol / vol Triton to remove unbound antibody.

69 Incubate dish with the appropriate secondary antibody conjugated with a fluorochrome of choice diluted in PBS - $0.2 \% \mathrm{vol} / \mathrm{vol}$ Triton - $1 \% \mathrm{wt} / \mathrm{vol}$ BSA at room temperature for 1 hour. In the same incubation also counterstain the nuclei with a nuclear dye such as Hoechst.

70 Perform two washes of 5 minutes with PBS - $0.2 \%$ vol / vol Triton to remove unbound antibody and one wash of 5 minutes with PBS.

71 Carefully aspirate the last PBS wash from the dish and add 1 drop of fluorescence mounting medium.

72 Put a coverslip on top of the dish to protect the specimen and avoid evaporation.

73 Image cells under a fluorescence microscope equipped with filters for the nuclear dye and the secondary antibody of choice.

\section{Step 74-99: Myogenic differentiation induction}

Timing: 1 day for transduction, 7 days for expansion of transduced cells, 8 days for differentiation, 1 day for immunofluorescence staining HEDEMs/HIDEMs lentiviral transduction with MyoD-ER(T)

74 Plate $1 \times 10^{5}$ HEDEMs/HIDEMs in a $35 \mathrm{~mm}$ dish in Proliferation Medium. 
75 When the cells are fully attached to the culture dish, thaw the MyoD-ER(T) lentiviral vector on ice and calculate the volume necessary to transduce cells with a multiplicity of infection (MOI) of 1,10 and 50 .

76 The following formula can be used at this purpose:

$\mu \mathrm{l}$ of virus needed $=$ number of cells to infect $x$ desired $\mathrm{MOI} /$ number of cells to infect $x$ desired $\mathrm{MOI}$

- CAUTION: work involving the use of viral vectors must be carried under a class two cabinet. Appropriately inactivate any residual lentiviral vector particles on surfaces and liquids that went in contact with it before their disposal.

- CRITICAL STEP: Titrate the MOI in order to find the amount of lentiviral vector that allows the cell culture to differentiate in myosin heavy chain $(\mathrm{MyHC})$-positive myotubes with an efficiency $>50 \%$. Differentiation efficiency can be assessed only after transduction. We suggest performing experiments with the cells that have the highest differentiation efficiency to $\mathrm{MOI}$ rate (i.e. the best differentiation with the lowest amount of lentiviral vector).

77 Dilute the lentiviral vector in $1 \mathrm{ml}$ of Proliferation medium supplemented with $1 \mu \mathrm{l}$ of Polybrene.

78 Remove medium from the $35 \mathrm{~mm}$ dish of MyoD-ER(T)-HEDEMs/HIDEMs and replace it with the $1 \mathrm{ml}$ of viral suspension. Incubate the cells for 12 hours at $37^{\circ} \mathrm{C}$ with $5 \% \mathrm{CO}_{2}$ and 3 to $5 \% \mathrm{O}_{2}$.

79 Remove medium and wash plate twice with PBS. Put fresh Proliferation Medium on cells.

80 Incubate the cells at $37^{\circ} \mathrm{C}$ with $5 \% \mathrm{CO}_{2}$ and 3 to $5 \% \mathrm{O}_{2}$ and inspect daily.

81 Expand cells as described in steps 41-44.

Differentiation assay and immunofluorescence for myosin heavy chain

82 Prepare Matrigel-coated $35 \mathrm{~mm}$ dishes.

83 Plate 1.5/2 $\times 10^{5}$ MyoD-ER(T)-HEDEMs/HIDEMs on a Matrigel-coated dish.

84 Incubate cells in growth medium at $37^{\circ} \mathrm{C}$ with $5 \% \mathrm{CO}_{2}$ and 3 to $5 \% \mathrm{O}_{2}$. 
85 Check cells daily and add $1 \mathrm{mM} \mathrm{4OH}$-Tamoxifen to Proliferation Medium when cells reach $90-100 \%$ confluence.

86 After 24 hours, replace Proliferation Medium with fresh Differentiation Medium supplemented with $1 \mathrm{mM} 4 \mathrm{OH}$-Tamoxifen.

87 Inspect cultures daily for myotubes formation. Replace half of the Differentiation Medium daily. Myotubes are usually identifiable in culture starting from 3 after the first Tamoxifen addition.

- CRITICAL STEP: differentiated cultures are delicate as myotubes detach easily when the plates are not handled gently. Media change should be done slowly and the medium should be added drop by drop on the sidewall of the plate.

88 From 6 to 7 days after the second Tamoxifen administration and the switch to Differentiation Medium the cell culture should be predominantly composed of multinucleated myotubes. These cultures are now ready to be analysed. Wash the differentiated plate gently with PBS twice and fix it with $4 \% \mathrm{wt} /$ vol paraformaldehyde for 10 minutes at RT.

- CAUTION: Paraformaldehyde is extremely toxic and must be handled under a chemical cabinet.

- PAUSE POINT: fixed cells can be kept with PBS at $4^{\circ} \mathrm{C}$ for at least two weeks before proceeding with the staining.

89 Permeabilise cells with PBS - $0.2 \%$ vol / vol Triton - $1 \%$ wt / vol BSA for 30 minutes at room temperature.

90 Remove permeabilising solution and incubate with $10 \%$ vol / vol animal serum for 30 minutes at room temperature to block non-specific binding sites.

91 Remove animal serum and incubate the dish with anti-myosin heavy chain (MyHC) primary antibody for 1 hour at room temperature.

- CRITICAL STEP: another differentiated dish or a sector of the same dish needs be incubated with secondary antibody and nuclear dye alone and hence used to assess the eventual non-specific binding of 
the secondary antibody to the sample and to evaluate the eventual level of background.

92 Perform three washes of 5 minutes with PBS $-0.2 \%$ vol / vol Triton to remove unbound antibody.

93 Incubate dish with any anti-mouse secondary antibody conjugated with a fluorochrome of choice diluted 1:500 in PBS $-0.2 \%$ vol / vol Triton - $1 \%$ wt / vol BSA at room temperature for 1 hour. In the same incubation also counterstain the nuclei with a nuclear dye such as Hoechst (1:250).

94 Perform two washes of 5 minutes with PBS - $0.2 \%$ vol / vol Triton to remove unbound antibody and one wash of 5 minutes with PBS.

95 Carefully aspirate the last PBS wash from the dish and add 1 drop of fluorescence mounting medium.

96 Put a coverslip on top of the dish to protect the specimen and avoid evaporation.

97 Image cells with a fluorescent microscope equipped with filters for the nuclear dye and the secondary antibody of choice. Take at least 10 random field pictures of the stained dish, using a microscope equipped with a $20 \mathrm{X}$ magnification lens (total magnification 200X).

98 Merge nuclear dye images with MyHC images and count the total number of nuclei. Then count only the number of nuclei localized within MyHC positive myotubes.

99 Apply the following formula to obtain the differentiation efficiency percentage: Number of nuclei within MyHC positive myotubes x 100 / Total number of nuclei of the field

\section{Step 100-107: Tumour formation assay to test in vivo safety profile Timing: 2 hours for cell injection and 4 months minimum follow up (depending on specific animal regulations)}

100 Detach the cells by trypsinization as described in points 41-43.

101 Discard the supernatant, resuspend the cell pellet by tapping at the bottom of the tube and resuspend it in at least $10 \mathrm{ml}$ of PBS. 
102 Centrifuge cell suspension at $232 \mathrm{~g}$ for 5 minutes.

103 Discard the supernatant and resuspend pellet in PBS to a final concentration of $2 \times 10^{6}$ cells / $150 \mu$ l (the volume of each injection).

104 Bring cells to the room designated for animal work and prepare mice for procedure according to your animal licence.

- CRITICAL STEP: all the animal work must obtain ethical approval and needs to be carried out in accordance to the animal regulation of your country and institution.

105 Inject $150 \mu \mathrm{l}$ of the cell suspension subcutaneously in the back or in the dorsal flank of immunodeficient mice (e.g., scid/beige, NOD or NSG strains). HeLa cells can be used as a positive control for tumour formation.

106 Screen the animals twice a week for the presence of growing subcutaneous masses. A minimum follow-up (followed by necropsy) of 4 months is highly recommended.

- CRITICAL STEP: monitor mice closely for clinical signs associated with tumour growth necessitating immediate culling (e.g., cachexia, dehydration, ulceration, infection).

107 In case of tumour mass formation of more than $10 \mathrm{~mm}$ of diameter, proceed to humanely kill the animal in order not to cause pain or significant discomfort.

\section{TIMING}

Steps 1-40: From pluripotent cells to mesoangioblast-like cells 18-21 days Step 41-44: Expansion of HEDEMs/HIDEMs minimum 7-10 days (depending on the number of cells required)

Step 45-50: Cryopreservation of HEDEMs/HIDEMs 1 hour Step 51-73: Characterisation of HEDEMs/HIDEMs 1 day for FACS analysis, 1 day for immunofluorescence staining

Step 74-99: Myogenic differentiation induction 1 day for transduction, 7 days for expansion of transduced cells, 8 days for differentiation, 1 day for immunofluorescence staining 
Step 100-107: Tumour formation assay to test in vivo safety profile 2 hours for cell injection and 4 months minimum follow up (depending on specific animal regulations)

\section{TROUBLESHOOTING TABLE}

\begin{tabular}{|c|c|c|c|}
\hline Step & Problem & Possible reason & Possible solution \\
\hline $\begin{array}{l}11 \\
\text { and } \\
22\end{array}$ & $\begin{array}{l}\text { Poor cell } \\
\text { survival. }\end{array}$ & $\begin{array}{l}\text { Some human } \\
\text { ES/iPS cell } \\
\text { cultures are } \\
\text { more sensitive } \\
\text { to single-cell } \\
\text { passaging. }\end{array}$ & $\begin{array}{l}\text { Seed higher cell concentrations } \\
\text { (e.g., } 2 X, 3 X \text { and } 5 X \text { ) to prevent } \\
\text { sub-optimal cell density due to poor } \\
\text { cell survival. It is advisable to } \\
\text { continue the protocol with the plate } \\
\text { that had the best survival and hence } \\
\text { appropriate density the day after } \\
\text { plating. }\end{array}$ \\
\hline 17 & $\begin{array}{l}\text { Cells do not } \\
\text { detach after } 2 \\
\text { hours in } \\
\text { dissociation } \\
\text { media. }\end{array}$ & $\begin{array}{l}\text { Some HIDEMs } \\
\text { lines strongly } \\
\text { adhere to the } \\
\text { Matrigel coating } \\
\text { making difficult } \\
\text { to detach them. }\end{array}$ & $\begin{array}{l}\text { Collect the dissociation media } \\
\text { containing the cells that have } \\
\text { already detached from the dish, } \\
\text { wash the dish once with PBS and } \\
\text { perform a short trypsinization at } \\
37^{\circ} \mathrm{C} \text { ( } 2-3 \text { minutes). Collect the cell } \\
\text { and proceed to step } 18 .\end{array}$ \\
\hline 24 & $\begin{array}{l}\text { The culture } \\
\text { appears } \\
\text { heterogeneous } \\
\text { with cell of } \\
\text { different } \\
\text { morphologies } \\
\text { coexisting in } \\
\text { the same dish. }\end{array}$ & $\begin{array}{l}\text { In feeder- } \\
\text { dependent } \\
\text { cultures some } \\
\text { residual } \\
\text { inactivated } \\
\text { feeder-layer } \\
\text { cells might be } \\
\text { carried into this } \\
\text { step. }\end{array}$ & $\begin{array}{l}\text { No action is required: inactivated } \\
\text { feeder layer cells are gradually lost } \\
\text { in the following steps and the } \\
\text { culture will become homogenous. }\end{array}$ \\
\hline
\end{tabular}




\section{ANTICIPATED RESULTS}

The protocol discussed here enables the efficient derivation of expandable mesoangioblast-like cells from both human ES and iPS cells (respectively HEDEMs and HIDEMs) that can then be easily differentiated into skeletal muscle cells (see Figure 1 for a schematic overview of the entire method). The derivation of HEDEMs/HIDEMs entails different steps, from pluripotent colonies to single cells resembling mesoangioblasts, which can be expanded before or after transduction with a Tamoxifen-regulated MyoD cassette. Figure 2 shows representative images of the morphology of the cell cultures at the different steps of the protocol.

HEDEMs/HIDEMs are characterised by a good proliferation potential with some cell lines able to generate over a period of 30 days up to $10^{12}$ cells starting from $5 \times 10^{5}$ (see Figure 3). A decreased proliferation rate might be observed upon MyoD-ER(T) transduction but still MyoD-ER(T)-HEDEMs/HIDEMs are capable of a significant expansion. This expansion potential supports the theoretical feasibility of translating this iPS cell-based approach to possible clinical settings, where billion cells per patient might be required and where cell availability/expansion is often a major bottleneck. We observed a slight decrease in proliferation of feeder-free HIDEMs compared with feeder-dependent HIDEMs derived from the same iPS cell colonies. However fewer lines were tested in comparison with feeder-dependent cultures, therefore this observation might be related to variability normally existing amongst different cell lines. Nonetheless, possible issues of reduced proliferation could always be overcome by increasing the amount of colonies in the starting iPS cell populations.

HEDEMs/HIDEMs express surface markers that can be assessed by means of fluorescence activated cell sorting as shown in Figure 4. In detail, HEDEMs/HIDEMs express CD146 (a perivascular marker), CD13, CD49b and CD44. AP, a marker of a subpopulation of skeletal muscle pericytes, shows variable expression levels amongst different cell lines. In addition, it is possible to evaluate more accurately AP activity via enzymatic reaction as shown and described in Supplementary Figure 1b. Notably, even though some cell lines 
express low AP levels, this does not affect the quality of the final product provided that other markers (e.g. CD146, CD13, CD44, CD49b) and parameters (e.g. in vitro differentiation assays) are met. Cells have to be negative or only weakly positive for CD56, SSEA4 and CD31. Representative percentages of positivity for all the different markers quoted above are shown in Supplementary Table 1. Furthermore, HEDEMs/HIDEMs do not display any significant residual expression of pluripotency-associated markers and this can be easily detected by an immunofluorescence analysis for Sox2, Nanog and Oct4 expression (Supplementary Figure 1a).

Once HEDEMs/HIDEMs have been characterised for their surface markers, they can be differentiated into multinucleated skeletal myotubes. To this aim, the use of a Tamoxifen-activated MyoD (MyoD-ER(T)) synchronises the differentiation of the whole culture. In order to obtain optimal results in terms of both cell proliferation and skeletal muscle differentiation, it is good practice to titrate the multiplicity of infection (MOI) of the MyoD-ER(T) lentiviral vector for every newly generated line. You should aim at having a differentiation efficiency of at least $50 \%$ of the total population (although we have observed differentiation efficiency above $90 \%$ with lines infected with a $\mathrm{MOI}<5$ ). Representative images of differentiated HEDEM/HIDEM lines can be found in Figure 5. The differentiation efficiency of each line is calculated by counting the number of nuclei inside MyHC positive cells over the total number of nuclei in at least ten randomly selected fields of the differentiated dishes (20X magnification; Supplementary Table 2). The ratio, expressed as percentage, is an index of the differentiation efficiency of the examined cell line. We have also incidentally observed formation of sarcomeric striations and spontaneous twitching of myotubes derived from HIDEMs after 8 days in myogenic differentiation medium (Supplementary Video 1). However, as this is not observed frequently, we do not rely on these parameters to monitor the efficiency of the protocol, which indeed is best achieved by using MyHC immunofluorescence staining.

Tumorigenic assays and transplantation experiments of HEDEMs/HIDEMs in immunodeficient mice demonstrate that the procedure is safe. For all the cell 
lines tested, no tumours were found after a minimum of 4 months follow-up. Assessment of regenerative potential of the final product is then performed by cell transplantation in mouse models of muscle regeneration, as recently detailed in a specific video-protocol ${ }^{14}$.

\section{FIGURE LEGENDS}

Figure 1. Workflow of the protocol to generate myogenic cells from human pluripotent stem cells via differentiation into mesoangioblast-like cells and transient MyoD activation.

Figure 2. Representative images showing the expected cell morphology along the protocol. Phase contrast pictures displaying cell morphology starting from pluripotent colonies (left column), through the various steps of the protocol (middle columns) until the final product. The established HIDEM/HEDEM cell lines are shown in the right column. (Scale bar $100 \mu \mathrm{m}$ ).

Figure 3. Representative number of cells obtained in one month of culture. The bar graph depicts the total number of cells derived from culturing healthy donor, disease-specific (LGMD2D and DMD) HIDEMs and HEDEMs over a period of 30 days, starting from $5 \times 10^{5}$ cells ( $\log 10$ scale, each line in duplicate). LGMD2D: limb girdle muscular dystrophy 2D; DMD: Duchenne muscular dystrophy. Please note that DMD HIDEMs were also genetically corrected with a human artificial chromosome containing the human dystrophin genetic locus (DYS-HAC) $^{11,50 .}$

Figure 4. Analysis of HEDEM/HIDEM surface markers by flow cytometry. The panel shows representative flow cytometry histograms of HIDEMs (left column), FF HIDEMs (middle column) and HEDEMs (right column). The histograms of unstained controls are shown in black whereas the samples 
stained with fluorochrome-conjugated antibodies are overlaid in red. A minimum number of $10^{4}$ events are shown for each histogram.

Figure 5. Myogenic differentiation of HEDEMs/HIDEMs with MyoD-ER(T). The panel shows four different lines of HIDEMs and one line of HEDEMs differentiated into skeletal myotubes after administration of two pulses of $4 \mathrm{OH}$ Tamoxifen, assessed by immunofluorescence staining for myosin heavy chain $(\mathrm{MyHC})$. The top row shows nuclei stained with Hoechst; differentiated myotubes are shown in the middle row. The lower part of the panel shows the merged images used to quantify the efficiency of differentiation (detailed in Supplementary Table 2; scale bar $75 \mu \mathrm{m}$ ).

\section{SUPPLEMENTARY INFORMATION}

\section{Supplementary Figure 1. Additional cell characterisation: pluripotency} analysis and alkaline phosphatase staining. (a) Representative immunofluorescence staining for the pluripotency factors Nanog, Oct4 and Sox2. Feeder-free HIDEMs are negative for all the markers and are shown in the left part of the panel. On the right hand side, stained feeder-free iPS cells are shown as positive control (scale bar $50 \mu \mathrm{m}$ ). (b) The histogram on the left hand side shows absence of AP signal in one HIDEM line, whereas the picture on the right had side shows AP activity detected with enzymatic reaction (purple/black precipitate; scale bar $50 \mu \mathrm{m}$ ).

Supplementary Video 1. The video shows a myotube derived from differentiated DMD HIDEMs twitching in culture at day 8 in myogenic differentiation medium. Sarcomeric striations are visible in their characteristic structure of alternate dark and light bands (640X magnification).

Protocol for alkaline phosphatase staining (Supplementary figure 1b) 
- Fix dishes of HEDEMs/HIDEMs with $4 \%$ (wt/vol) paraformaldehyde solution for 5 minutes at room temperature. Wash once with PBS, add $1 \mathrm{ml}$ of alkaline phosphatase staining solution and incubate in the dark at room temperature. Wait for the development of the reaction protecting it from light. Check under inverted microscope for the appearance of the staining every 15 minutes up to 2 hours of incubation with staining solution. Consider the use of paraformaldehyde-fixed HeLa cells as positive control for the reaction.

\begin{tabular}{|l|c|c|c|}
\hline \multirow{2}{*}{ Marker } & \multicolumn{3}{|c|}{ Percentage of positive cells } \\
\cline { 2 - 4 } & HIDEMs & FF HIDEMs & HEDEMs \\
\hline CD13 & $99.9 \%$ & $73.3 \%$ & $70.4 \%$ \\
CD31 & $0 \%$ & $4.4 \%$ & $0.1 \%$ \\
CD44 & $99.7 \%$ & $98.3 \%$ & $99.8 \%$ \\
CD45 & $0.3 \%$ & $4.9 \%$ & $0.4 \%$ \\
CD49b & $99.9 \%$ & $90.7 \%$ & $99.8 \%$ \\
CD56 & $0.3 \%$ & $1.6 \%$ & $0.5 \%$ \\
\hline CD146 & $84.8 \%$ & $78.7 \%$ & $99.2 \%$ \\
SSEA4 & $0.9 \%$ & $6.3 \%$ & $1.5 \%$ \\
\hline
\end{tabular}

Supplementary Table 1. Quantification of FACS analysis. The table displays the percentage of cells (HIDEMs, FF HIDEMs and HEDEMs, presented in Figure 4) positive for different surface marker expression analysed by FACS. The percentages were calculated gating and subtracting the unstained sample from the stained one. 


\begin{tabular}{l|c|c|c|c|}
\hline Cell line & $\begin{array}{c}\text { Nuclei } \\
\text { outside } \\
\text { MyHC+ } \\
\text { cells }\end{array}$ & $\begin{array}{c}\text { Nuclei } \\
\text { inside } \\
\text { MyHC+ } \\
\text { cells }\end{array}$ & $\begin{array}{c}\text { Total } \\
\text { number of } \\
\text { nuclei }\end{array}$ & $\begin{array}{c}\text { Calculated } \\
\text { efficiency of } \\
\text { differentiation }\end{array}$ \\
\hline HIDEMs & 35 & 101 & 136 & $74.3 \%$ \\
DMD HIDEMs & 76 & 268 & 344 & $77.9 \%$ \\
LGMD2D HIDEMs & 13 & 155 & 168 & $92.3 \%$ \\
FF HIDEMs & 0 & 181 & 181 & $100 \%$ \\
HEDEMs & 50 & 175 & 207 & $75.1 \%$ \\
\hline
\end{tabular}

\section{Supplementary Table 2. Quantification of myogenic differentiation.}

Representative results obtained by counting the single images of the different lines shown in Figure 5. Nuclei outside and inside MyHC-positive cells are counted and then the ratio of nuclei inside MyHC-positive cells / total nuclei is used to calculate the differentiation efficiency.

\section{AUTHOR CONTRIBUTIONS}

SM and MFMG performed the experiments with the help of MR, analysed the data and wrote the manuscript; SD performed experiments on feeder-free iPS cells and HIDEMs, discussed and analysed results with TVD and MKC; SB performed proliferation analysis and analysed results; ML performed live imaging experiments, analysed and discussed results; FST conceived the initial protocol, discussed and analysed results with all co-authors and wrote the paper.

\section{AKNOWLEDGMENTS}

The authors thank Peter Andrews (University of Sheffield, UK) and the UK Stem Cell Bank for kindly supplying Shef 6 human ES cells and Giulio Cossu (University of Manchester, UK) for the initial support in establishing this technology. The authors are also grateful to the following biobanks and colleagues for some of the cells used in this study and/or in its relative original article $^{16}:$ 1) Marina Mora and The "Cells, tissues and DNA from patients with neuromuscular diseases Biobank", member of the Telethon Network of Genetic 
Biobanks (project no. GTB12001), funded by Telethon Italy, and of the EuroBioBank network; 2) Benedikt Schoser, Peter Schneiderat and The Muscle Tissue Culture Collection (MTCC), part of the German network on muscular dystrophies (MD-NET, service structure S1, 01GM0601) and the German network for mitochondrial disorders (mito-NET, project D2, 01GM0862) funded by the German ministry of education and research (BMBF, Bonn, Germany). The Muscle Tissue Culture Collection is a partner of EuroBioBank (www.eurobiobank.org) and TREAT-NMD (www.treat-nmd.eu); 3) Yvan Torrente, Maurizio Moggio and the Telethon Network of Genetic Biobanks at Ospedale Maggiore Policlinico, Milan, Italy; 4) Mitsuo Oshimura and Yasuhiro Kazuki (Tottori University, Yonago, Japan) for the DMD iPS cells.

Work in the Tedesco laboratory is supported by the European Union's Seventh Framework Programme for research, technological development and demonstration under grant agreement no. 602423 (PluriMes), Takeda New Frontier Science, the UK Medical Research Council (MRC) and Biotechnology and Biological Sciences Research Council (BBSRC), Duchenne Parent Project Onlus, Muscular Dystrophy Campaign, Duchenne Children's Trust and the Duchenne Research Fund. MKC, TVD, SD and ML were supported by the Fund for Scientific Research (FWO) and Association Française contre les Myopathies (AFM); SD and ML performed most of the work described here in a collaborative project as visiting PhD students at University College London.

\section{COMPETING FINANCIAL INTERESTS}

The work described in this article is partially covered by the patent application no. PCT/GB2013/050112; publication no. WO2013108039 A1. FST is the principal investigator of a grant funded by Takeda New Frontier Science programme and provided speaking and consulting services to Takeda Pharmaceuticals International Inc. via UCL Consultants. The other authors do not have any direct financial relationships with the funding bodies that sponsored this research. 


\section{REFERENCES}

1 Mercuri, E. \& Muntoni, F. Muscular dystrophies. Lancet 381, 845-860, doi:10.1016/S0140-6736(12)61897-2 (2013).

2 Benedetti, S., Hoshiya, H. \& Tedesco, F. S. Repair or replace? Exploiting novel gene and cell therapy strategies for muscular dystrophies. The FEBS journal 280, 4263-4280, doi:10.1111/febs.12178 (2013).

3 Fairclough, R. J., Perkins, K. J. \& Davies, K. E. Pharmacologically targeting the primary defect and downstream pathology in Duchenne muscular dystrophy. Curr Gene Ther 12, 206-244 (2012).

4 Perie, S. et al. Autologous myoblast transplantation for oculopharyngeal muscular dystrophy: a phase I/lla clinical study. Molecular therapy : the journal of the American Society of Gene Therapy 22, 219-225, doi:10.1038/mt.2013.155 (2014).

5 Dellavalle, A. et al. Pericytes of human skeletal muscle are myogenic precursors distinct from satellite cells. Nature cell biology 9, 255-267, doi:10.1038/ncb1542 (2007).

6 Sacco, A. et al. Short telomeres and stem cell exhaustion model Duchenne muscular dystrophy in mdx/mTR mice. Cell 143, 1059-1071, doi:S0092-8674(10)01361-9 [pii] 10.1016/j.cell.2010.11.039 (2010).

7 Blau, H. M., Webster, C. \& Pavlath, G. K. Defective myoblasts identified in Duchenne muscular dystrophy. Proceedings of the National Academy of Sciences of the United States of America 80, 4856-4860 (1983).

8 Cohn, R. D. et al. Disruption of DAG1 in differentiated skeletal muscle reveals a role for dystroglycan in muscle regeneration. Cell 110, 639-648 (2002).

9 Kudryashova, E., Kramerova, I. \& Spencer, M. J. Satellite cell senescence underlies myopathy in a mouse model of limb-girdle muscular dystrophy $2 \mathrm{H}$. The Journal of clinical investigation 122, 1764-1776, doi:10.1172/JCI59581 (2012). 
10 Cassano, M. et al. Alpha sarcoglycan is required for FGF-dependent myogenic progenitor cell proliferation in vitro and in vivo. Development, doi:dev.070706 [pii] 10.1242/dev.070706 (2011).

11 Tedesco, F. S. et al. Transplantation of genetically corrected human iPSCderived progenitors in mice with limb-girdle muscular dystrophy. Science translational medicine 4, 140ra189, doi:10.1126/scitranslmed.3003541 (2012).

12 Yamanaka, S. Induced pluripotent stem cells: past, present, and future. Cell Stem Cell 10, 678-684, doi:10.1016/j.stem.2012.05.005 (2012).

13 Goldberg-Cohen, I., Beck, G., Ziskind, A. \& Itskovitz-Eldor, J. Vascular cells. Methods in enzymology 418, 252-266, doi:10.1016/S00766879(06)18015-5 (2006).

14 Gerli, M. F., Maffioletti, S. M., Millet, Q. \& Tedesco, F. S. Transplantation of induced pluripotent stem cell-derived mesoangioblast-like myogenic progenitors in mouse models of muscle regeneration. Journal of visualized experiments : JoVE, e50532, doi:10.3791/50532 (2014).

$15 \mathrm{Li}, \mathrm{O}$. et al. Human iPSC-derived mesoangioblasts, like their tissuederived counterparts, suppress $T$ cell proliferation through IDO- and PGE2-dependent pathways [v1; ref status: indexed]. F1000 Research 2, doi:10.12688/f1000research 2-24.v1\#sthash.UOUHsrhi.dpuf (2013).

16 Dey, J. et al. MyoD is a tumor suppressor gene in medulloblastoma. Cancer research 73, 6828-6837, doi:10.1158/0008-5472.CAN-13-0730-T (2013).

17 Rideout, W. M., 3rd et al. Progressive increases in the methylation status and heterochromatinization of the myoD $\mathrm{CpG}$ island during oncogenic transformation. Molecular and cellular biology 14, 6143-6152 (1994).

18 Ferreira, L. M. \& Mostajo-Radji, M. A. How induced pluripotent stem cells are redefining personalized medicine. Gene 520, 1-6, doi:10.1016/j.gene.2013.02.037 (2013). 
19 Barberi, T. et al. Derivation of engraftable skeletal myoblasts from human embryonic stem cells. Nature medicine 13, 642-648, doi:10.1038/nm1533 (2007).

20 Darabi, R. et al. Human ES- and iPS-derived myogenic progenitors restore DYSTROPHIN and improve contractility upon transplantation in dystrophic mice. Cell stem cell 10, 610-619, doi:10.1016/j.stem.2012.02.015 (2012).

21 Awaya, T. et al. Selective development of myogenic mesenchymal cells from human embryonic and induced pluripotent stem cells. PloS one 7, e51638, doi:10.1371/journal.pone.0051638 (2012).

22 Goudenege, S. et al. Myoblasts derived from normal hESCs and dystrophic hiPSCs efficiently fuse with existing muscle fibers following transplantation. Molecular therapy : the journal of the American Society of Gene Therapy 20, 2153-2167, doi:10.1038/mt.2012.188 (2012).

23 Tanaka, A. et al. Efficient and reproducible myogenic differentiation from human iPS cells: prospects for modeling Miyoshi Myopathy in vitro. PloS one 8, e61540, doi:10.1371/journal.pone.0061540 (2013).

24 Borchin, B., Chen, J. \& Barberi, T. Derivation and FACS-mediated purification of $\mathrm{PAX} 3+/ \mathrm{PAX} 7+$ skeletal muscle precursors from human pluripotent stem cells. Stem cell reports 1, 620-631, doi:10.1016/j.stemcr.2013.10.007 (2013).

$25 \mathrm{Xu}, \mathrm{C}$. et al. A zebrafish embryo culture system defines factors that promote vertebrate myogenesis across species. Cell 155, 909-921, doi:10.1016/j.cell.2013.10.023 (2013).

26 Takahashi, K. et al. Induction of pluripotent stem cells from adult human fibroblasts by defined factors. Cell 131, 861-872, doi:10.1016/j.cell.2007.11.019 (2007).

27 Aflatoonian, B. et al. Generation of Sheffield (Shef) human embryonic stem cell lines using a microdrop culture system. In vitro cellular \& developmental biology. Animal 46, 236-241, doi:10.1007/s11626-0109294-2 (2010). 
28 Watanabe, K. et al. A ROCK inhibitor permits survival of dissociated human embryonic stem cells. Nature biotechnology 25, 681-686, doi:10.1038/nbt1310 (2007).

29 Sanes, J. R. The basement membrane/basal lamina of skeletal muscle. The Journal of biological chemistry 278, 12601-12604, doi:10.1074/jbc.R200027200 (2003).

30 Malinda, K. M. In vivo matrigel migration and angiogenesis assay. Methods in molecular biology 467, 287-294, doi:10.1007/978-1-59745241-0_17 (2009).

31 Ponce, M. L. Tube formation: an in vitro matrigel angiogenesis assay. Methods in molecular biology 467, 183-188, doi:10.1007/978-1-59745241-0_10 (2009).

32 Grefte, S., Vullinghs, S., Kuijpers-Jagtman, A. M., Torensma, R. \& Von den Hoff, J. W. Matrigel, but not collagen I, maintains the differentiation capacity of muscle derived cells in vitro. Biomedical materials 7, 055004, doi:10.1088/1748-6041/7/5/055004 (2012).

33 Kuhl, U., Timpl, R. \& von der Mark, K. Synthesis of type IV collagen and laminin in cultures of skeletal muscle cells and their assembly on the surface of myotubes. Developmental biology 93, 344-354 (1982).

34 Yin, H., Price, F. \& Rudnicki, M. A. Satellite cells and the muscle stem cell niche. Physiological reviews 93, 23-67, doi:10.1152/physrev.00043.2011 (2013).

35 Tonlorenzi, R., Dellavalle, A., Schnapp, E., Cossu, G. \& Sampaolesi, M. Isolation and characterization of mesoangioblasts from mouse, dog, and human tissues. Current protocols in stem cell biology Chapter 2, Unit 2B 1, doi:10.1002/9780470151808.sc02b01s3 (2007).

36 Kimura, E. et al. Cell-lineage regulated myogenesis for dystrophin replacement: a novel therapeutic approach for treatment of muscular dystrophy. Human molecular genetics 17, 2507-2517, doi:10.1093/hmg/ddn151 (2008). 
37 Dorchies, O. M. et al. The anticancer drug tamoxifen counteracts the pathology in a mouse model of duchenne muscular dystrophy. The American journal of pathology 182, 485-504, doi:10.1016/j.ajpath.2012.10.018 (2013).

38 Nakano-Okuno, M., Borah, B. R. \& Nakano, I. Ethics of iPSC-Based Clinical Research for Age-Related Macular Degeneration: PatientCentered Risk-Benefit Analysis. Stem cell reviews 10, 743-752, doi:10.1007/s12015-014-9536-x (2014).

39 Cyranoski, D. Japanese woman is first recipient of next-generation stem cells. Nature, doi:doi:10.1038/nature.2014.15915 (2014).

40 Bejjani, B. A. \& Shaffer, L. G. Application of array-based comparative genomic hybridization to clinical diagnostics. The Journal of molecular diagnostics : JMD 8, 528-533, doi:10.2353/jmoldx.2006.060029 (2006).

41 Workman, P. et al. Guidelines for the welfare and use of animals in cancer research. British journal of cancer 102, 1555-1577, doi:10.1038/sj.bjc.6605642 (2010).

42 Montini, E. et al. The genotoxic potential of retroviral vectors is strongly modulated by vector design and integration site selection in a mouse model of HSC gene therapy. The Journal of clinical investigation 119, 964975, doi:10.1172/JCl37630 (2009).

43 Aiuti, A. et al. Lentiviral hematopoietic stem cell gene therapy in patients with Wiskott-Aldrich syndrome. Science 341, 1233151, doi:10.1126/science.1233151 (2013).

44 Biffi, A. et al. Lentiviral hematopoietic stem cell gene therapy benefits metachromatic leukodystrophy. Science 341, 1233158, doi:10.1126/science.1233158 (2013).

45 Matrai, J. et al. Hepatocyte-targeted expression by integrase-defective lentiviral vectors induces antigen-specific tolerance in mice with low genotoxic risk. Hepatology 53, 1696-1707, doi:10.1002/hep.24230 (2011).

46 Matrai, J., Chuah, M. K. \& VandenDriessche, T. Recent advances in lentiviral vector development and applications. Molecular therapy : the 
journal of the American Society of Gene Therapy 18, 477-490, doi:10.1038/mt.2009.319 (2010).

47 Oshimura, M., Uno, N., Kazuki, Y., Katoh, M. \& Inoue, T. A pathway from chromosome transfer to engineering resulting in human and mouse artificial chromosomes for a variety of applications to bio-medical challenges. Chromosome research : an international journal on the molecular, supramolecular and evolutionary aspects of chromosome biology, doi:10.1007/s10577-014-9459-z (2015).

48 Tedesco, F. S. Human artificial chromosomes for Duchenne muscular dystrophy and beyond: challenges and hopes. Chromosome research : an international journal on the molecular, supramolecular and evolutionary aspects of chromosome biology, doi:10.1007/s10577-014-9460-6 (2015).

49 Follenzi, A. \& Naldini, L. Generation of HIV-1 derived lentiviral vectors. Methods in enzymology 346, 454-465 (2002).

50 Tedesco, F. S. et al. Stem cell-mediated transfer of a human artificial chromosome ameliorates muscular dystrophy. Science translational medicine 3, 96ra78, doi:10.1126/scitransImed.3002342 (2011). 